\title{
Comparative Statics of Central Bank Liquidity Management: Some Insights
}

\author{
Indranil Bhattacharyya and Satyananda Sahoo \\ Executive Office, Qatar Central Bank, P.O. Box No. 1234, Doha, Qatar \\ Correspondence should be addressed to Satyananda Sahoo, ssahoo77@gmail.com
}

Received 2 December 2010; Accepted 31 May 2011

Academic Editor: Taufiq Choudhry

Copyright ( $) 2011$ I. Bhattacharyya and S. Sahoo. This is an open access article distributed under the Creative Commons Attribution License, which permits unrestricted use, distribution, and reproduction in any medium, provided the original work is properly cited.

The paper demonstrates the efficacy of liquidity management through both the rate and quantum channels. Using the concepts of autonomous and discretionary liquidity, the paper derives the optimal policy mix of instruments which can be used for stabilizing the price of liquidity. For effective liquidity management, the sufficient condition highlighted in the paper has important implications for developing market-related monetary policy instruments, particularly in emerging market economies.

\section{Introduction}

Liquidity management by central banks typically refers to the framework, set of instruments, and the rules that the monetary authority follows in managing systemic liquidity, consistent with the ultimate goals of monetary policy. In this regard, central banks modulate liquidity conditions by varying both the level of short-term interest rates and influencing the supply of bank reserves in the interbank market. While central bank liquidity management has short-term effects in financial markets, its long-term implications for the real sector and on price level are more profound. It is from this standpoint that a central bank decides to adjust its market operations over a chosen time horizon to reflect its policy stance.

A major part of the existing literature on liquidity management focuses on assessing monetary policy stance (which is more of a long-term nature) rather than the strategy of monetary operations (which is essentially short term), mainly concentrating on advanced economies. The emphasis of the paper, however, is on the day-to-day market operations in EME central banks which have received less attention in the literature given the complexity of their economic environment and inadequacy of markets and instruments but has assumed critical importance in the wake of the global financial meltdown.
While liquidity management in most advanced country central banks is conducted in a setting where the financial system is usually in a liquidity shortage mode, it is more varied in emerging market economies (EMEs) often oscillating between surplus and shortage conditions. In recent years, capital flows have been a major factor affecting liquidity conditions in a large number of EMEs. Since the absorptive capacity of capital inflows in EMEs is limited to the extent of the size of their real economic activity and sophistication of financial markets, large inflows can have a destabilizing impact by fuelling asset bubbles and engendering inflation expectations. On the other hand, sudden reversal of inflows (due to flight to safety and quality), as witnessed during the recent crisis, also pose a huge threat to financial stability in these economies. Therefore, the task of liquidity management has become even more complex and challenging in case of EME central banks, being bestowed with the responsibility of steering the economy while safeguarding financial stability.

The challenges to liquidity management were brought to the fore during the subprime crisis of 2007 leading to the global financial crisis of 2008. In August 2007, money markets, largely in industrial economies but also in EMEs, became frozen even as the subprime crisis was unraveling in the US. As the crisis underwent a metamorphosis to reach global proportions, EMEs faced the additional challenge 
from panic outflows of capital. To contain the crisis of confidence and ease financial conditions, central banks used both conventional and unconventional measures to inject liquidity. The use of unconventional measures was warranted to unfreeze money and credit markets as the regular monetary policy transmission mechanism got seriously impaired by the crisis. These measures were in the form of (i) increasing central bank liquidity provision to financial institutions, both in domestic and foreign currency; (ii) intervening directly in wider segments of the financial market; (iii) purchasing long-term government bonds; (iv) supporting specific institutions [1]. Moreover, central banks enhanced the scope of liquidity management beyond traditional counterparties and broadened the basket of acceptable securities as collateral.

Against this backdrop, the paper develops a simple model of liquidity management using the framework of partitioning liquidity into autonomous and discretionary factors. It demonstrates the efficacy of both the quantum and rate channels in managing liquidity. While this approach has been used by many EMEs in the past, its recent adoption by several advanced economies was in focus, particularly in the wake of the global crisis. For central banks following an inherent rule of offsetting autonomous liquidity conditions through discretionary measures, the paper derives combinations of optimal policy mix and a robust sufficient condition for stabilization of market interest rates. The structure of the paper is the following. Section 2 provides a synoptic view of the theoretical underpinnings of liquidity management. While the framework of liquidity management is presented in Section 3, the policy implications of the results are discussed in Section 4. The concluding observations are presented in Section 5.

\section{Theory of Liquidity Management-A Primer}

The theory of liquidity management can be clearly distinguished from the "optimal instrument choice problem" literature initiated by Poole [2]. Although subsequent research often refers to the terms "operating procedures" and "instrument choice", they concentrate on macroeconomic strategy of the central bank rather than the actual day-today monetary policy implementation. In practice, central bank liquidity management links the daily monetary policy operations, through the operating target, to the overall macroeconomic developments by influencing the yield curve.

Liquidity management takes place within an operational framework which, in itself, is set against the backdrop of the existing economic environment. In this regard, a theory of liquidity management has three elements affecting the optimal choice of the operational framework and the liquidity management strategy. First, the institutional features of the interbank money market need to be efficient in terms of smooth transfer of funds between lenders and borrowers. Second, the forecasting techniques of liquidity indicators employed by central banks, although not perfect, are better than those of market participants. Third, changes in the operational target of the central bank cannot be completely anticipated by money market players; that is, there is a potential "announcement effect" of surprising the market through changes in the operational target.

Supply and demand for funds in the short-term interbank market determine their price, the overnight rate. The supply of reserves is given by the net effect of the liquidity provided through both autonomous factors and by money market operations of the central bank. The demand for reserves arises from the banks' need to fulfill reserve requirements and maintain some "excess" reserves for settlement balances, the price for which is the short-term interbank market rate. In this regard, the overnight market plays a key role as it has the least maturity and is, therefore, the short end of the yield curve.

The market for bank reserves is complex owing to its inherent uncertain behavior. In a system of minimum reserve requirements which have only to be met, on average, over a maintenance period, banks essentially face an intertemporal optimization problem when minimizing the cost of holding required reserves. The opportunity cost of holding excess reserves on one day is the interbank overnight rate on that day. Banks will thus have an incentive to hold reserve surpluses (or accumulate reserve deficits) whenever the market rate is low (high) in relation to future expected overnight rates within the maintenance period. This behavior on the part of banks will tend to stabilize overnight market rates as, in order for the market to clear, rates will tend to be aligned with future expected overnight rates within the maintenance period. Overnight rates, thus, will be determined not only by current or past conditions but also by expectations about liquidity conditions in the remainder of the reserve maintenance period.

As discussed earlier, central banks have superior information on all supply parameters of bank reserves, namely, (i) it has better forecasts of autonomous factors; (ii) it controls its market operations; (iii) it knows more about its future course of policy action. However, the actions of the central bank, both through market operations and media interactions, may in itself reveal part of its superior information set to market participants, which creates a signal extraction problem [3]. For the central bank, a potential way out of this problem is to publish the forecasts of autonomous factors.

In the literature, several formulations of central bank policy actions, usually represented through a monetary policy reaction function, have been suggested including databased indices depicting central bank operating procedures [4], Taylor-type instrument rules [5], and various variants thereof as well as narrative approaches based on "reading" monetary and financial information [6]. The operating target variables in central bank reaction functions have been monetary aggregates and short-term interest rates or both. Where a monetary aggregate in the form of bank reserves or its variant is targeted, it is useful to partition bank reserves into autonomous and discretionary liquidity components, since central banks are seldom able to gear their entire balance sheet for the purpose of liquidity management on account of other objectives of monetary policy. 
TABLE 1: Autonomous and discretionary liquidity factors in a central bank balance sheet.

\begin{tabular}{ll}
\hline Liabilities & Assets \\
\hline$\left(L_{1}\right)$ currency & $\left(A_{1}\right)$ credit to government \\
$\left(L_{2}\right)$ bank reserves & $\left(A_{2}\right)$ credit to banks \\
$\left(L_{3}\right)$ net other liabilities & $\left(A_{3}\right)$ net foreign assets \\
\hline Total liabilities & Total assets \\
\hline
\end{tabular}

\section{A Framework of Liquidity Management}

In recent years, liquidity conditions have been assessed by partitioning bank balances with the central bank in terms of their balance sheet flows emanating from "discretionary" policy operations and other "autonomous" factors [7-9]. Autonomous liquidity (AL) is the sum of primary liquidity available to banks stemming from regular central banking functions as the currency authority and banker to banks and the government.

In a stylized central bank balance sheet (Table 1), AL could comprise the claims on the government $\left(A_{1}\right)$ and the rest of the world $\left(A_{3}\right)$ netted for leakages from the banking system, such as currency $\left(L_{1}\right)$ and net other liabilities $\left(L_{3}\right)$, that is,

$$
\mathrm{AL}=A_{1}+A_{3}-L_{1}-L_{3}
$$

(from Table 1).

The typical autonomous factors are amount of banknotes in circulation, foreign exchange assets, and volume of government deposits. These are simply those items in the central bank balance sheet that are not current account holdings of credit institutions. Thus, AL is the summary measure of the primary liquidity that flows to the banking system.

On the other hand, discretionary liquidity (DL), the balance primary money flow to the banking system, arises out of the central bank's money market operations, that is,

$$
\mathrm{DL}=A_{2} \text {. }
$$

Central banks can-and often do-predict AL and the total demand for bank reserves $\left(R^{d}\right)$ (conventionally decomposed into required reserves (RR) and the demand for excess reserves $\left(\mathrm{ER}^{d}\right)$, inclusive of settlement balances, etc). The net liquidity (NL), prior to central bank liquidity operations, could then be estimated, ex ante, through

$$
\mathrm{NL}=R^{d}=\left(\mathrm{RR}+\mathrm{ER}^{d}\right)-\mathrm{AL}
$$

that is, the excess demand for bank reserves net of autonomous flows.

If the central bank decides to maintain the existing liquidity conditions (interest rates), it could offset NL with $\mathrm{DL}$ ( $\Rightarrow$ total supply of bank reserves $\left(R^{s}=\mathrm{AL}+\mathrm{DL}\right)=$ total demand for bank reserves) [10]. Intuitively, if DL does not fully offset NL, then ceteris paribus, interest rates change to clear the market for bank reserves. The realised liquidity in the market for bank reserves is, ex post, simply the balances banks maintain with the central bank.
Thus,

total reserves $=\mathrm{RR}+\mathrm{ER}=\mathrm{AL}+\mathrm{DL}=L_{2}, \quad\left(\Longrightarrow R^{d}=R^{s}\right)$.

In addition to the quantum of liquidity, short-term interest rates also react speedily to changes in the price of DLthe price at which liquidity is made available from the central bank to the market-such as changes in the central bank policy rate. Thus, while changes in the policy rate have an instantaneous (direct) "announcement effect" on the market interest rate, they also have an indirect effect on the cost of liquidity within the banking system. As such, the "announcement effect" gets reinforced by the "liquidity effect" of policy changes.

The market for bank reserves evolves largely through the dynamic interaction between the central bank and depository institutions. While classification of bank reserves in terms of borrowed and nonborrowed reserves has its own utility, the AL-DL measures appear relatively more appealing in case of many EME central banks who have the combined responsibilities of implementing monetary policy and managing government debt. The critical importance of the ALDL reserve concepts lies in the fact that they blend into both the monetary and interest rate targeting frameworks as well as the intermediate regimes, which have gained popularity after the recent crisis.

3.1. The Model. We develop a model of the market for bank reserves in which the central bank uses the array of instruments at its disposal for stabilizing the price of liquidity $[10,11]$. While the demand for required reserves depends on the prescribed reserve requirement ratio $(r)$ by the central bank, excess reserves (ER), inclusive of settlement balances, is usually maintained as a precautionary buffer for unforeseen contingencies. The demand for ER is inversely related to its opportunity cost, that is, the market interest rate $\left(i_{\mathrm{mr}}\right)$ and to the cost of avoiding shortfall in reserves, that is, the central bank policy rate $\left(i_{\mathrm{pr}}\right)$. In other words, commercial banks would like to hold lower ER when the market interest rate is high since drawing down unremunerated ER and redeploying them in the interbank money market would earn $i_{\mathrm{mr}}$. When the policy rate is higher, banks would prefer to hold large excess reserves as a buffer as any potential shortfall in reserve position would entail resorting to central bank credit facilities which entails the cost $i_{\mathrm{pr}}$. Thus, the demand for ER would be lower at the margin when the policy rate is higher.

Therefore, the demand for reserves $\left(R^{d}\right)$ can be represented as a function of the market interest rate, the central bank policy rate, and the required reserve ratio $(r)$ prescribed by the central bank, that is,

$$
R^{d}=R^{d}\left(i_{\mathrm{mr}}, i_{\mathrm{pr}}, r\right)
$$

where $R_{i_{\mathrm{mr}}}^{d^{\prime}}<0, R_{i_{\mathrm{pr}}}^{d^{\prime}}<0, R_{r}^{d^{\prime}}>0$ indicate the inverse relationship of the demand for reserves with the market interest rate and the central bank policy rate but direct relationship with the reserve requirement ratio. 
By definition, the supply of bank reserves $\left(R^{s}\right)$ is the sum of autonomous liquidity (AL) and discretionary liquidity (DL), that is,

$$
R^{s}=\mathrm{AL}+\mathrm{DL} .
$$

In the light of the global financial crisis and the various measures taken by central banks to stabilize the price of liquidity in the interbank market, DL (or policy liquidity) encompasses both conventional policy instruments and unconventional quantitative easing measures. Among conventional measures, reserve requirements have been used in many EMEs (e.g., China, India, Russia, and Latin America) to (i) counter capital inflows; (ii) enhance the effectiveness of monetary control; (iii) restore the transmission mechanism of monetary policy during periods of stress (possibly serving as an alternative to quantitative easing or largescale asset purchases by advanced economies); (iv) counter financial imbalances associated with excessive credit growth. The recent experience in these economies suggests that adjustments in reserve requirements may have helped to stabilize interbank rates and influence market rates in a way that moderated capital flows. They may also have helped to smooth credit growth during the expansionary and contractionary phases of the business cycle [12].

As mentioned earlier, DL depends on conventional instruments, namely, (i) liquidity adjustment through changes in $r$ (which impacts on both the demand and supply of reserves); (ii) supplying reserves to banks through net open market purchases $(Q)$ and the price $\left(i_{\mathrm{pr}}\right)$ at which funds are made available from the central bank. In times of stress, DL can also be provided through unconventional measures in the form of (i) asset repurchase programs (similar to net open market purchases); (ii) establishing swap lines with foreign central banks for augmenting foreign currency liquidity; (iii) establishing emergency credit lines from the central bank (Some countries also resorted to Term Auction Facility, Primary Dealer Credit Facility, Term Securities Lending Facility, and Commercial Paper Funding Facility during the crisis). Without loss of generality and keeping our analysis confined to normal times, DL can be represented in a stylized form as a function of the central bank policy rate $\left(i_{\mathrm{pr}}\right)$, the reserve requirement ratio $(r)$, and net open market purchases $(Q)$ by the central bank, that is,

$$
\mathrm{DL}=\mathrm{DL}\left(i_{\mathrm{pr}}, r, Q\right), \quad \text { where } \mathrm{DL}_{i_{\mathrm{pr}}}^{\prime}<0, \mathrm{DL}_{r}^{\prime}<0, \mathrm{DL}_{Q}^{\prime}>0 .
$$

(On the other hand, when the central bank makes net open market sales (i.e., $Q<0$ ), it reduces liquidity from the system, such that $\mathrm{DL}_{\mathrm{Q}}^{\prime}>0$ holds). It is reasonable to assume $\mathrm{DL}_{i_{\mathrm{pr}}}^{\prime}<0$ since resorting to central bank credit is usually frowned upon in normal times as it would entail higher cost for availing marginal credit. Since most EMEs suffer from liquidity surplus situations, they are expected to balance their liquidity mismatches without accessing too much of central bank credit facilities. Consequently, any rate hike would result in lower recourse to central bank credit. Similarly, a reduction in reserve requirement increases liquidity of the banking system (by releasing impounded reserve balances), while net open market purchases absorb liquidity from the banking system.

In functional form, the supply of bank reserves can be represented as

$$
R^{s}=R^{s}\left(\mathrm{AL}, \mathrm{DL}, i_{\mathrm{mr}}\right)
$$

(from (5), (6), and (7)), where $R_{\mathrm{AL}}^{s^{\prime}}>0, R_{\mathrm{DL}}^{s^{\prime}}>0, R_{i_{\mathrm{mr}}}^{s^{\prime}}>0$ indicate an increase in the supply of bank reserves due to an increase in autonomous and discretionary liquidity. Similarly, an increase in the market interest rate also augments the supply of reserves as commercial banks with surplus funds would deploy more funds in the interbank market earning $i_{\mathrm{mr}}$. The market for bank reserves is equilibrated at the shortterm interest rate $i_{\mathrm{mr}}^{*}$ such that the demand equals the supply of bank reserves, that is,

$$
R^{d}\left(i_{\mathrm{mr}}^{*}, i_{\mathrm{pr}}, r\right)=R^{s}\left(\mathrm{AL}, \mathrm{DL}, i_{\mathrm{mr}}^{*}\right),
$$

which, assuming monotonicity in $i_{\mathrm{mr}}$, can be represented in the inverse functional form as

$$
i_{\mathrm{mr}}=f^{-1}\left(i_{\mathrm{pr}}, r, \mathrm{AL}, \mathrm{DL}\right)
$$

(from (7))

$$
\begin{array}{r}
i_{\mathrm{mr}}=g\left(i_{\mathrm{pr}}, r, \mathrm{AL}, \mathrm{DL}\left(i_{\mathrm{pr}}, r, Q\right)\right), \quad \text { where } g_{i_{\mathrm{pr}}}^{\prime}>0, \\
g_{r}^{\prime}>0, \quad g_{\mathrm{AL}}^{\prime}<0, \quad g_{\mathrm{DL}}^{\prime}<0
\end{array}
$$

(from (7) and (10)).

The market interest rate is positively related to the central bank policy rate and reserve requirement as any increase in the two results in a firming up of the market interest rate though expectations of higher interest rates. On the other hand, any increase in the supply of bank reserves through increase in $\mathrm{AL}$ or $\mathrm{DL}$ or both reduces the market interest rate by augmenting liquidity in the market for bank reserves.

The change in market interest rates can be obtained by totally differentiating (11), that is,

$$
\begin{aligned}
d i_{\mathrm{mr}}= & g_{\mathrm{pr}_{\mathrm{pr}}}^{\prime} d i_{\mathrm{pr}}+g_{r}^{\prime} d r+g_{\mathrm{AL}}^{\prime} d \mathrm{AL} \\
& +g_{\mathrm{DL}}^{\prime} \mathrm{DL}_{i_{\mathrm{pr}}}^{\prime} d i_{\mathrm{pr}}+g_{\mathrm{DL}}^{\prime} \mathrm{DL}_{r}^{\prime} d r+g_{\mathrm{DL}}^{\prime} \mathrm{DL}_{\mathrm{Q}}^{\prime} d Q \\
= & \left(g_{i_{\mathrm{pr}}}^{\prime}+g_{\mathrm{DL}}^{\prime} \mathrm{DL}_{i_{\mathrm{pr}}}^{\prime}\right) d i_{\mathrm{pr}}+\left(g_{r}^{\prime}+g_{\mathrm{DL}}^{\prime} \mathrm{DL}_{r}^{\prime}\right) d r \\
& +g_{\mathrm{AL}}^{\prime} d \mathrm{AL}+g_{\mathrm{DL}}^{\prime} \mathrm{DL}_{Q}^{\prime} d Q .
\end{aligned}
$$

From (12), note that a change in $i_{\mathrm{pr}}$, ceteris paribus, impacts on $i_{\text {mr }}$ through two ways, namely, the direct "announcement (signaling) effect" $\left(g_{i_{\mathrm{pr}}}^{\prime}\right)$, which is instantaneous, and the indirect "liquidity effect" $\left(g_{\mathrm{DL}}^{\prime} \mathrm{DL}_{i_{\mathrm{pr}}}^{\prime}\right)$ as a result of the change in the cost of liquidity available from the central bank as discussed earlier. A similar impact is noted from changes in the reserve requirement ratio (direct signaling effect $\left(g_{r}^{\prime}\right)$ and indirect liquidity effect $\left.\left(g_{\mathrm{DL}}^{\prime} \mathrm{DL}_{r}^{\prime}\right)\right)$.

The following partial derivatives delineate the impact of changes in the determinants of liquidity conditions on 
the market interest rate. From (7) and (11), it can be inferred that

$$
\begin{aligned}
& \left(\frac{\delta i_{\mathrm{mr}}}{\delta i_{\mathrm{pr}}}\right)=\left(g_{i_{\mathrm{pr}}}^{\prime}+g_{\mathrm{DL}}^{\prime} \mathrm{DL}_{i_{\mathrm{pr}}}^{\prime}\right)>0, \\
& \text { [assuming } d \mathrm{AL}=d r=d Q=0 \text { ], } \\
& \left(\frac{\delta i_{\mathrm{mr}}}{\delta r}\right)=\left(g_{r}^{\prime}+g_{\mathrm{DL}}^{\prime} \mathrm{DL}_{r}^{\prime}\right)>0, \quad\left[d \mathrm{AL}=d i_{\mathrm{pr}}=d Q=0\right], \\
& \left(\frac{\delta i_{\mathrm{mr}}}{\delta \mathrm{AL}}\right)=g_{\mathrm{AL}}^{\prime}<0, \quad\left[d r=d i_{\mathrm{pr}}=d Q=0\right], \\
& \left(\frac{\delta i_{\mathrm{mr}}}{\delta Q}\right)=g_{\mathrm{DL}}^{\prime} \mathrm{DL}_{\mathrm{Q}}^{\prime}<0, \quad\left[d r=d i_{\mathrm{pr}}=d \mathrm{AL}=0\right],
\end{aligned}
$$

that is, while an increase in the policy rate and reserve requirement, ceteris paribus, hardens market interest rates both through the signaling impact and the liquidity effect ((13) and (14)), an increase in AL and $Q$, ceteris paribus, softens $i_{\text {mr }}$ by augmenting the supply of reserves directly and by an infusion of liquidity through $Q$ ((15) and (16)).

It is now worthwhile to turn to the mechanics of stabilization of market interest rates (i.e., $d i_{\mathrm{mr}}=0$ ). Since the central bank's main objective is to stabilize the price of liquidity, it can seek to plug/offset the perceived market liquidity gap/surplus by compensating changes in DL. In this regard, a simple policy rule could be offsetting AL with a compensating DL such that

$$
d \mathrm{DL}=-d \mathrm{AL} \Longrightarrow d R^{s}=0,
$$

(from (6)).

Following this rule, the impact on $i_{\mathrm{mr}}$ can be derived from (12) using (7) and (17):

$$
\begin{aligned}
d i_{\mathrm{mr}}= & {\left[g_{i_{\mathrm{pr}}^{\prime}}^{\prime}+\left(g_{\mathrm{DL}}^{\prime}-g_{\mathrm{AL}}^{\prime}\right) \mathrm{DL}_{i_{\mathrm{pr}}}^{\prime}\right] d i_{\mathrm{pr}} } \\
& +\left[g_{r}^{\prime}+\left(g_{\mathrm{DL}}^{\prime}-g_{\mathrm{AL}}^{\prime}\right) \mathrm{DL}_{r}^{\prime}\right] d r+\left[\left(g_{\mathrm{DL}}^{\prime}-g_{\mathrm{AL}}^{\prime}\right) \mathrm{DL}_{\mathrm{Q}}^{\prime}\right] d Q
\end{aligned}
$$

From (18), a trivial solution is that there is no change in $i_{\mathrm{mr}}$ when $r, i_{\mathrm{pr}}$, and $Q$ remain unchanged. The more interesting case from the policy perspective is to analyze the impact of combinations of changes in $r, i_{\mathrm{pr}}$, and $Q$ on the stability of $i_{\mathrm{mr}}$. In the wake of the crisis, most central banks have taken the intermediate option of using both the quantity and rate channels for stabilizing market interest rates. Therefore, it is useful to look upon the efficacy of combinations of both channels for policy purposes by pairing policy instruments.

Case 1. The central bank could stabilize market interest rate by increasing (decreasing) reserve requirements and decreasing (increasing) the policy rate as demonstrated below.

Substituting $d i_{\mathrm{mr}}=0$ and $d Q=0$ in (18) and rearranging terms, we get

$$
\left[g_{i_{\mathrm{pr}}}^{\prime}+\left(g_{\mathrm{DL}}^{\prime}-g_{\mathrm{AL}}^{\prime}\right) \mathrm{DL}_{i_{\mathrm{pr}}}^{\prime}\right] d i_{\mathrm{pr}}=-\left[g_{r}^{\prime}+\left(g_{\mathrm{DL}}^{\prime}-g_{\mathrm{AL}}^{\prime}\right) \mathrm{DL}_{r}^{\prime}\right] d r
$$

or,

$$
d i_{\mathrm{pr}}=-\left[\frac{\left\{g_{r}^{\prime}+\left(g_{\mathrm{DL}}^{\prime}-g_{\mathrm{AL}}^{\prime}\right) \mathrm{DL}_{r}^{\prime}\right\}}{\left\{g_{i_{\mathrm{pr}}}^{\prime}+\left(g_{\mathrm{DL}}^{\prime}-g_{\mathrm{AL}}^{\prime}\right) \mathrm{DL}_{i_{\mathrm{pr}}}^{\prime}\right\}}\right](d r),
$$

$d i_{\text {pr }}$ and $d r$ are inversely related if and only if (iff) the $[\cdots]$ is positive. Given $g_{i_{\mathrm{pr}}}^{\prime}>0, g_{r}^{\prime}>0, \mathrm{DL}_{r}^{\prime}<0$, and $\mathrm{DL}_{i_{\mathrm{pr}}}^{\prime}<$ 0 , a sufficient condition for $[\cdots]$ to be positive is $\left(g_{\mathrm{DL}}^{\prime}-\right.$ $\left.g_{\mathrm{AL}}^{\prime}\right)<0 \Rightarrow\left|g_{\mathrm{DL}}^{\prime}\right|>\left|g_{\mathrm{AL}}^{\prime}\right|\left(\right.$ as $g_{\mathrm{DL}}^{\prime}<0$ and $\left.g_{\mathrm{AL}}^{\prime}<0\right)$, that is, if market interest rates are influenced to a greater extent by discretionary rather than autonomous liquidity. Thus, central banks could, ceteris paribus, stabilize liquidity conditions with a mix of offsetting adjustments in reserve requirements and the policy rate if and only if the market response to changes in discretionary liquidity is stronger than that to autonomous factors.

Case 2. Similarly, the central bank could stabilize $i_{\mathrm{mr}}$ by increasing (decreasing) reserve requirements and increasing (decreasing) $Q$. Again, substituting $d i_{\mathrm{mr}}=0$ and $d i_{\mathrm{pr}}=0$ in (18) and rearranging terms, we get

$$
\left[\left(g_{\mathrm{DL}}^{\prime}-g_{\mathrm{AL}}^{\prime}\right) \mathrm{DL}_{\mathrm{Q}}^{\prime}\right] d Q=-\left[g_{r}^{\prime}+\left(g_{\mathrm{DL}}^{\prime}-g_{\mathrm{AL}}^{\prime}\right) \mathrm{DL}_{r}^{\prime}\right] d r,
$$

or

$$
d Q=-\left[\frac{\left\{g_{r}^{\prime}+\left(g_{\mathrm{DL}}^{\prime}-g_{\mathrm{AL}}^{\prime}\right) \mathrm{DL}_{r}^{\prime}\right\}}{\left\{\left(g_{\mathrm{DL}}^{\prime}-g_{\mathrm{AL}}^{\prime}\right) \mathrm{DL}_{\mathrm{Q}}^{\prime}\right\}}\right](d r),
$$

that is, $d Q$ and $d r$ are positively related if and only if $[\cdots]$ is negative. Given $g_{r}^{\prime}>0, \mathrm{DL}_{r}^{\prime}<0$ and $\mathrm{DL}_{Q}^{\prime}>0$, the sufficient condition for $[\cdots]$ to be negative is $\left(g_{\mathrm{DL}}^{\prime}-g_{\mathrm{AL}}^{\prime}\right)<0 \Rightarrow$ $\left|g_{\mathrm{DL}}^{\prime}\right|>\left|g_{\mathrm{AL}}^{\prime}\right|$ as mentioned earlier. Hence, the central bank could ensure orderly conditions in the money market with a policy combination that pares reserve requirements (perhaps with a view to phase out a "blunt" instrument) and impound the resultant liquidity through net open market sales. Alternatively, it could increase liquidity through net open market purchases and sterilize its impact through increase in reserve requirements.

Case 3. Furthermore, the central bank could stabilize $i_{\mathrm{mr}}$ by increasing (decreasing) the policy rate and increasing (decreasing) Q. Again, substituting $d i_{\mathrm{mr}}=0$ and $d r=0$ in (18) and rearranging terms, we get

$$
\left[\left(g_{\mathrm{DL}}^{\prime}-g_{\mathrm{AL}}^{\prime}\right) \mathrm{DL}_{\mathrm{Q}}^{\prime}\right] d Q=-\left[g_{i_{\mathrm{pr}}}^{\prime}+\left(g_{\mathrm{DL}}^{\prime}-g_{\mathrm{AL}}^{\prime}\right) \mathrm{DL}_{i_{\mathrm{pr}}^{\prime}}^{\prime}\right] d i_{\mathrm{pr}}
$$

or

$$
d Q=-\left[\frac{\left\{g_{i_{\mathrm{pr}}^{\prime}}^{\prime}+\left(g_{\mathrm{DL}}^{\prime}-g_{\mathrm{AL}}^{\prime}\right) \mathrm{DL}_{i_{\mathrm{pr}}}^{\prime}\right\}}{\left\{\left(g_{\mathrm{DL}}^{\prime}-g_{\mathrm{AL}}^{\prime}\right) \mathrm{DL}_{\mathrm{Q}}^{\prime}\right\}}\right]\left(d i_{\mathrm{pr}}\right),
$$

that is, $d Q$ and $d i_{\text {pr }}$ are directly related if and only if $[\cdots]$ is negative. Given $g_{i_{\mathrm{pr}}}^{\prime}>0, \mathrm{DL}_{i_{\mathrm{pr}}}^{\prime}<0$ and $\mathrm{DL}_{Q}^{\prime}>0,[\cdots]$ is negative if the sufficient condition mentioned above holds. 
Therefore, the central bank could stabilize market liquidity through a policy of coupling a hike (reduction) in the policy rate accompanied by open market purchases (sales).

As evident from the common sufficient condition in each of the above three cases, short-term interest rates in the market for bank reserves could be stabilized through a mix of (i) countervailing changes in reserve requirements and the policy rate, and (ii) unidirectional changes by pairing (a) reserve requirements and OMO and (b) the policy rate and OMO. For effective stabilization of the market interest rate, the common "sufficient" condition requiring market interest rate sensitivity to discretionary liquidity be greater than that to autonomous liquidity changes is a robust result which underscores the potency of the central bank's discretionary use of policy instruments in fine-tuning liquidity. It is also a pointer that for successful liquidity management, central banks, particularly those in EMEs, should develop policy instruments which are more reflective of market sentiments. Central banks with a credible reputation would, thus, be able to influence market expectations as the announcement impact (which is consistent from the market perspective) would reinforce the liquidity effect of policy measures.

\section{Policy Implications}

The simple model of interest rate stabilization in the interbank money market developed in the paper provides several key insights. First, the partitioning of liquidity into autonomous and discretionary factors clearly delineates the liquidity flows emanating from central bank money market operations as against the evolution of autonomous liquidity movements originating from regular banking activities. Second, as demonstrated in the model, a simple policy rule of offsetting autonomous liquidity flows through policy intervention gives rise to alternative policy mix of coupling monetary policy instruments for stabilizing the price of liquidity in the interbank market. In this context, it may be noted that, hitherto, the conventional wisdom was to operate either through interest rates or by influencing the level of bank reserves. As pointed out earlier, the recent crisis has demonstrated the utility of an intermediate solution whereby market operations simultaneously influence both the rate and the quantum. It is important to note that several EMEs, perhaps for the lack of adequate financial instruments and depth of markets, were operating in such a framework for a long time which was considered more of an aberration rather than the rule. The recent crisis has been a revelation in this regard. Finally, the paper establishes a robust sufficient condition which states that market sensitivity to central bank liquidity operations has to be stronger than its response to autonomous factors for successful interest rate stabilization. This bears testimony to the fact that for market related monetary policy operations to be successful, the credibility and reputation of the central bank is extremely critical. The "open mouth operations" of the central bank can influence market expectations, if and only if, the former lives up to its commitments [13]. In this regard, EME central banks need to establish and strengthen their credentials of credibility through consistent actions.

In view of the recent crisis, central bank liquidity management has gained added importance both in advanced economies and EMEs. In this context, a key challenge is to forecast the autonomous factors for determining the course of market intervention as mentioned earlier. Among the autonomous factors, forecast for currency in circulation is relatively easier given the strong patterns of seasonality in the demand for currency. For example, currency demand is particularly higher during festive seasons and holidays. The more complex task is to arrive at any meaningful forecast of foreign exchange inflows and government balances which are extremely volatile. While government revenues have some seasonal factors in terms of quarterly tax collections, government expenditure schedules are often ad hoc and do not reflect any recognized pattern, being often driven by political decisions and uncertainty about resource mobilization. While it is difficult to overcome these challenges within a short period of time, greater coordination and synchronization of actions between the treasury and the monetary authority can help in institutionalizing data reporting systems which can facilitate the task of forecasting. Nevertheless, liquidity management for central banks can never be perfect. For example, as the assessment of both autonomous and discretionary factors by market participants remains uncertain given the signal extraction problem discussed earlier, the subjective joint probability distribution of the relevant liquidity factors would have a major impact on the evolving expectations of market participants about liquidity conditions. Thus, liquidity management is a skill which can only be honed over the medium term by minimizing the forecast errors and incorporating the feedback loop in the decision-making process of the central bank.

\section{Conclusion}

Summing up, the objective of the paper was to draw some perspectives on liquidity management pertaining to EMEs rather than developing a full-fledged liquidity assessment model. The main focus of the paper was on exploring the advantages of liquidity management through both quantum and rate channels, a feature specific to EMEs rather than advanced economies. In this regard, the stability condition demonstrated in the paper for developing market-based monetary policy instruments in the case of EMEs has an intuitive appeal. From this perspective, the paper's operational significance pertains to those EMEs having to manage liquidity surplus conditions arising either out of current account surplus or capital inflows. Finally, the objective of the paper was not about exploring the linkages between liquidity management and inflation control-the focus of all central bank monetary operations. In that sense, the paper pertains more to monetary policy strategy rather than monetary policy stance, which is more of a long term nature. Linking liquidity management to inflation outcomes, in itself, is a complex exercise requiring the incorporporation of the feedback-loop in the transmission mechanism of monetary 
policy in an intertemporal framework. This paper, however, would have served its purpose if it engenders further research in this direction.

\section{Acknowledgments}

The views expressed in this paper are those of the authors only and do not reflect that of the institution to which they belong. The authors are grateful to Dr. Taufiq Choudhry, the editor, and an anonymous referee for valuable comments and suggestions, although the usual disclaimer applies.

\section{References}

[1] M. Minegishi and B. Cournède, "Monetary policy responses to the crisis and exit strategies," OECD Economics Department Working Papers, no. 753, 2010.

[2] W. Poole, "Optimal choice of monetary policy instruments in a simple stochastic macro model," The Quarterly Journal of Economics, vol. 84, no. 2, pp. 197-216, 1970.

[3] U. Bindseil, "Central bank liquidity management: theory and euro area practice," 2000, http://www.ecb.int/events/pdf/conferences/1b.pdf.

[4] J. F. Boschen and L. O. Mills, "The effects of countercyclical monetary policy on money and interest rates: an evaluation of evidence from FOMC documents," Federal Reserve Bank of Philadelphia Working Paper, vol. 91, no. 20, 1991.

[5] J. B. Taylor, "Discretion versus policy rules in practice," Carnegie-Rochester Conference Series on Public Policy, no. 39, 1993.

[6] C. D. Romer and D. H. Romer, "Does monetary policy matter? A new test in the spirit of Friedman and Schwartz," in NBER Macroeconomics Annual, pp. 121-70, 1989.

[7] C. E. V. Borio, "The implementation of monetary policy in industrialized countries," Bank for International Settlements Economic Papers, no. 47, 1997.

[8] European Central Bank, The Monetary Policy of the European Central Bank, 2001.

[9] A. Schaechter, "Implementation of monetary policy and the central bank's balance sheet," International Monetary Fund Working Paper, no. 149, 2001.

[10] U. Bindseil, "Central bank forecasts of liquidity factors: quality, publication and the control of the overnight rate," The European Central Bank Working Paper, no. 70, 2001.

[11] C. E. Walsh, Monetary Theory and Policy, MIT Press, 1998.

[12] C. Montoro and R. Moreno, "The use of reserve requirements as a policy instrument in Latin America," Bank for International Settlements Quarterly Review, March 2011.

[13] S. Demiralp and O. Jorda, "The transmission of monetary policy via announcement effects," Department of Economics, University of California, Davis Working Paper Series, vol. 99, no. 6, 1999. 


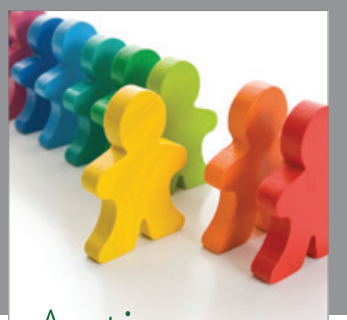

Autism

Research and Treatment
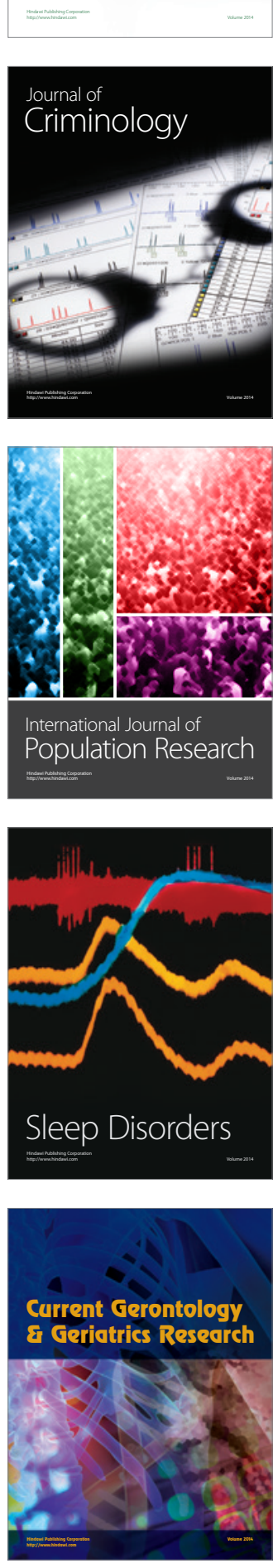
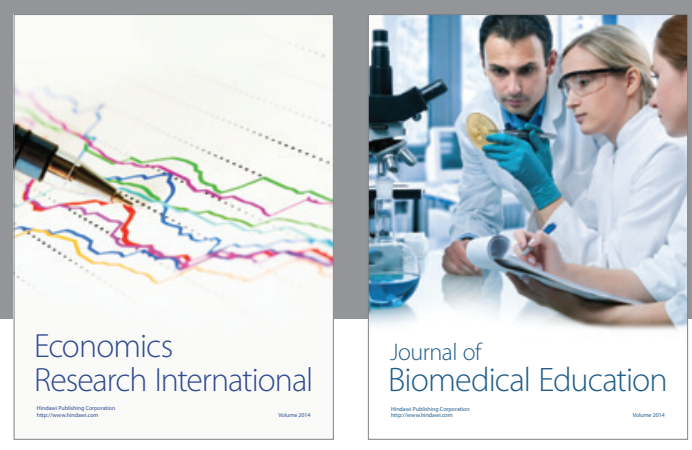

Journal of

Biomedical Education

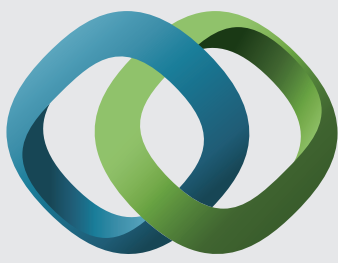

\section{Hindawi}

Submit your manuscripts at

http://www.hindawi.com
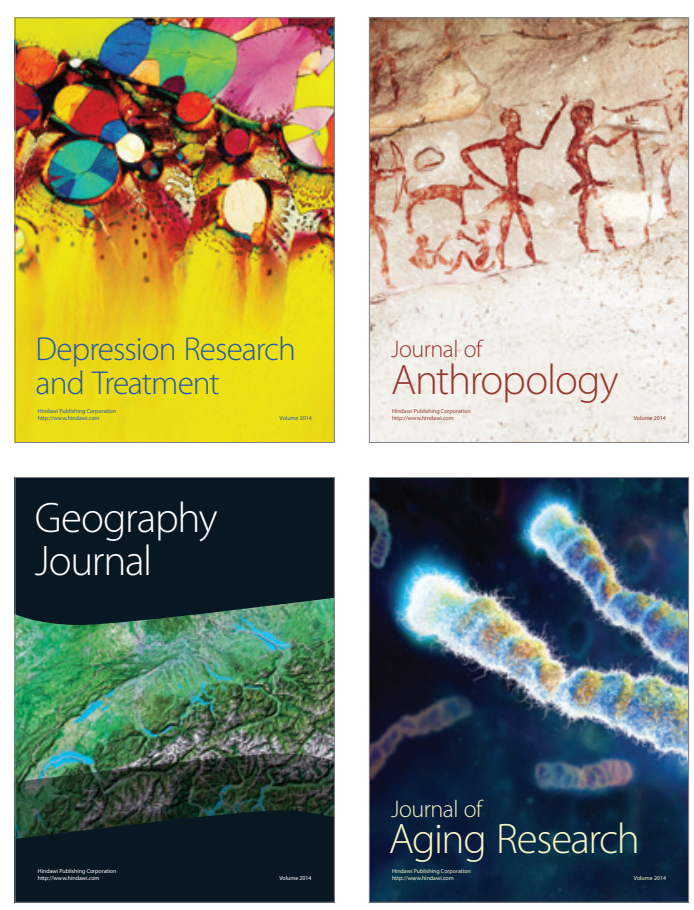

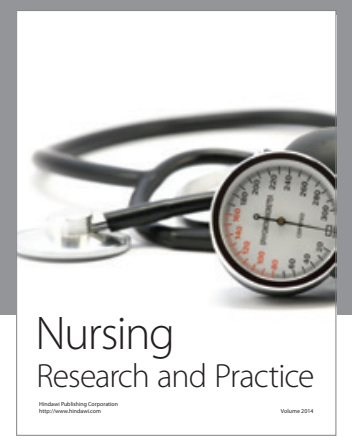

Nursing

Research and Practice

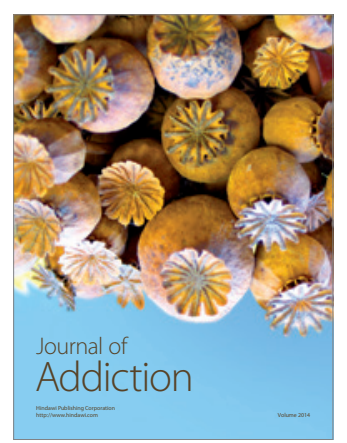

Child Development

Research

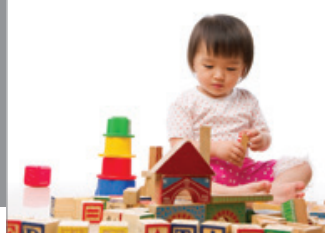

迥
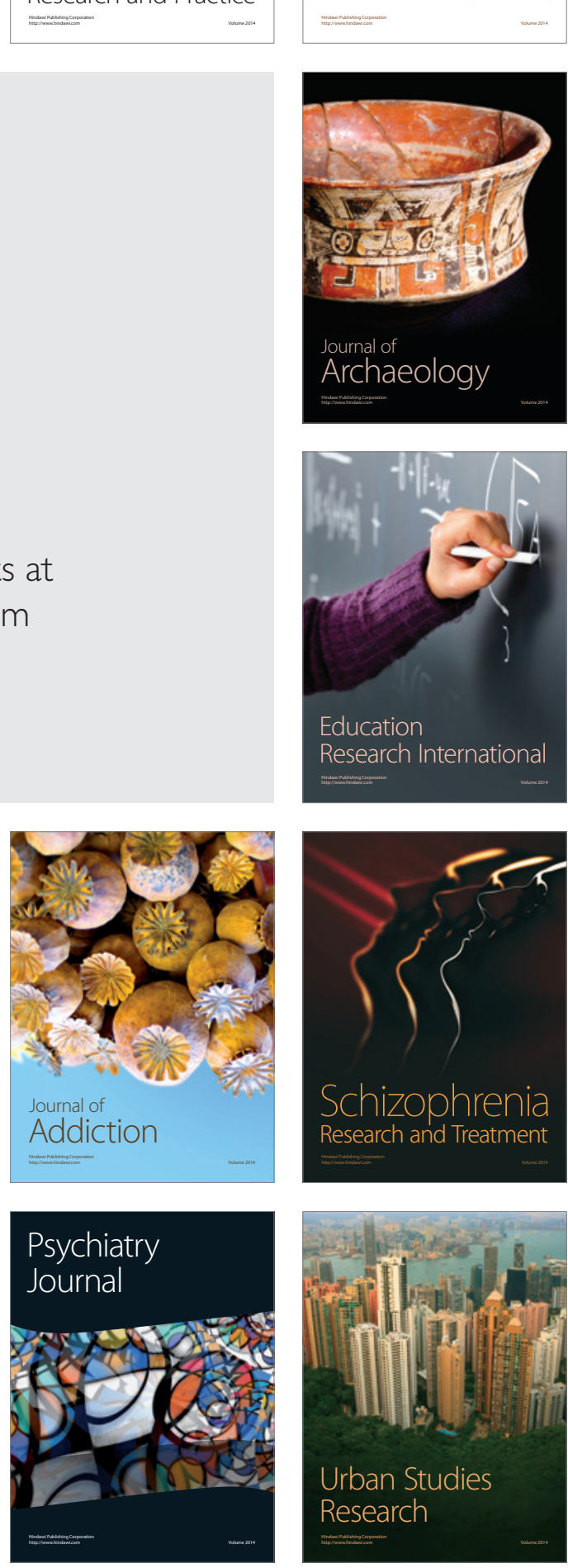